UCRL-JC-127445

PREPRINT

\title{
Mars Ascent Propulsion Options for Small Sample Return Vehicles
}

\author{
J. C. Whitehead
}

This paper was prepared for submittal to the American Institute of Aeronautics and Astronautics Joint Propulsion Conference and Exhibit Seattle, WA July 6-9, 1997

May 12, 1997

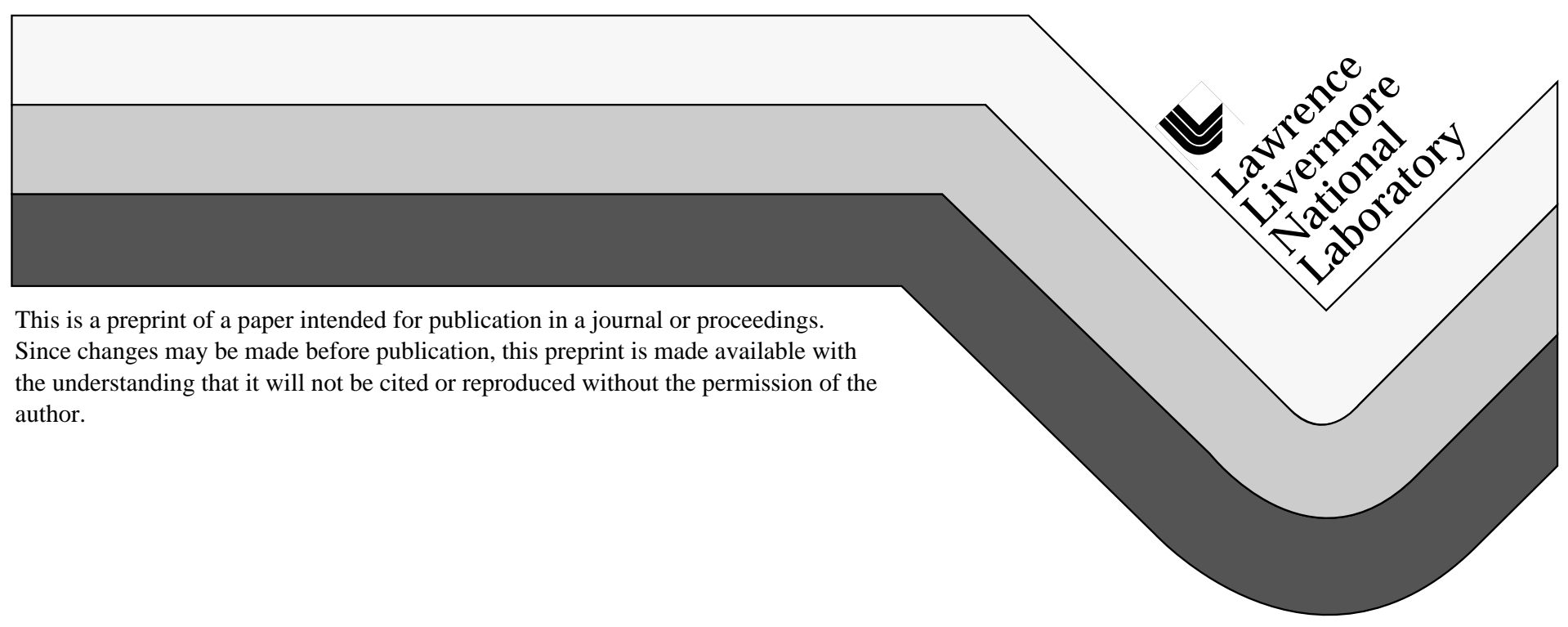




\section{DISCLAIMER}

This document was prepared as an account of work sponsored by an agency of the United States Government. Neither the United States Government nor the University of California nor any of their employees, makes any warranty, express or implied, or assumes any legal liability or responsibility for the accuracy, completeness, or usefulness of any information, apparatus, product, or process disclosed, or represents that its use would not infringe privately owned rights. Reference herein to any specific commercial product, process, or service by trade name, trademark, manufacturer, or otherwise, does not necessarily constitute or imply its endorsement, recommendation, or favoring by the United States Government or the University of California. The views and opinions of authors expressed herein do not necessarily state or reflect those of the United States Government or the University of California, and shall not be used for advertising or product endorsement purposes. 


\title{
MARS ASCENT PROPULSION OPTIONS FOR SMALL SAMPLE RETURN VEHICLES
}

\author{
John C. Whitehead* \\ Lawrence Livermore National Laboratory \\ Livermore, CA 94551
}

\begin{abstract}
$\underline{\text { Abstract }}$
An unprecedented combination of high propellant fraction and small size is required for affordable-scale Mars return, regardless of the number of stages, or whether Mars orbit rendezvous or in-situ propellant options are used. Conventional space propulsion technology is too heavy, even without structure or other stage subsystems. The application of launch vehicle design principles to the development of new hardware on a tiny scale is therefore suggested. Miniature pump-fed rocket engines fed by low pressure tanks can help to meet this challenge. New concepts for engine cycles using piston pumps are described, and development issues are outlined.
\end{abstract}

\section{Introduction}

NASA has bold plans to obtain Mars samples during the next decade, within a budget that permits sending at most $\sim 1000 \mathrm{~kg}$ to Mars per earth launch. Round trip mission options and concepts for propellant production on Mars have been studied extensively. However, virtually nothing has been written about the miniaturization of launch vehicles for Mars departure. This paper is an attempt to fill said void, by carefully examining both the problem and potential solutions. Key questions include: "What propellants should be used," "What hardware technology is appropriate," "What is the best number of stages," "How small can a practical Mars ascent vehicle be," and "What is the development timeline and cost?"

Affordable Mars sample return options under consideration are limited to approximately $\$ 100 \mathrm{M}$ for earth launch costs. They include an orbital rendezvous scenario based on a pair of Delta II class missions, ${ }^{1}$ and a direct-to-earth vehicle which is sent to Mars by a larger, more expensive earth launcher. ${ }^{2}$ The first of these options requires lifting a sample with rendezvous hardware to Mars orbit, given a landed mass of $\sim 300 \mathrm{~kg}$ as in the recent Pathfinder mission. The alternative would require $\sim 1000 \mathrm{~kg}$ on Mars

*Senior Member, AIAA

Copyright (C) 1997 by the Lawrence Livermore National Laboratory. Publishedby theAmerican Institute of Aeronautics and Astronautics, Inc. with permission. This work was performed under contract W-7405-Eng-48 with the U.S. DoE. to accelerate $\sim 50 \mathrm{~kg}$, including a cruise spacecraft and earth entry capsule, onto an earth return trajectory.

Figure 1 compares typical maneuvering requirements ${ }^{3}$ for Mars return to other propulsive maneuvers and spacecraft capabilities. Engines compete with propellant and tanks for a share of the same mass budget, so it is most difficult to achieve both high $\Delta \mathrm{v}$ and high acceleration together. These are plotted on independent axes to indicate why returning from Mars on any scale is more difficult than every rocket maneuver accomplished to date, except for earth launch. Moreover, Mars launch for an affordable sample return mission must be accomplished with a only a hundredth to a thousandth the mass of earth launch vehicles.

Herein, it is shown that achieving sufficiently high mass ratios on appropriate scales is beyond available propulsion technologies. Significant advances in small rocket hardware and custom stage design are required. It is critical to recognize this fact, since the necessary capability differs from what earth satellites and defense systems require. There is no "technology pipeline," as is the case with continually-advancing electronics, for example.

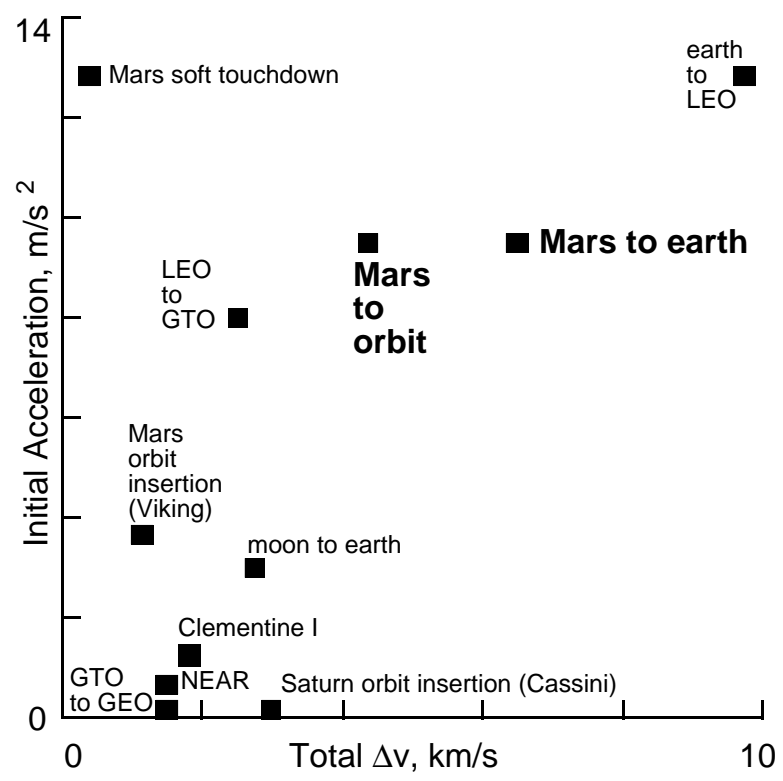

Figure 1. Mars launch compared to other maneuvers. 
The author's relevant experience ranges from SSTO analysis 4 to the development of a pump-fed engine cycle and its unique hardware on a tiny scale. Approximately 2 $\mathrm{kg}$ of lightweight propulsion hardware, including the tank, enabled a test vehicle's $21 \mathrm{~kg}$ launch mass to include $60 \%$ propellant and $\sim 30 \%$ non-propulsion hardware. ${ }^{5}$

\section{Propellant fractions and staging}

This section quantifies the need for high mass ratio propulsion on a tiny scale. It is shown that there is a difficult choice between the extreme propellant fractions required for single-stage options, and the extreme miniaturization required for upper stages.

If gravity and drag losses are considered, reaching Mars orbit requires approximately $2 / 3$ the $\Delta v$ of the Mars-to-earth maneuver. For convenience, this paper defines Mars orbit so that this is precisely true. Figure 2 shows vehicle propellant fractions as functions of specific impulse, for several staging options. Specifically, the vertical axis shows the fraction dictated by the rocket equation: mass expelled by a given stage, divided by gross vehicle mass just prior to operation of that stage.

Insight into the trade between Isp and hardware mass for Mars ascent can be gleaned from Figure 2. For large velocity changes at high acceleration, tanks and engines together constitute a large fraction of dry mass. Therefore, small reductions in Isp are welcome if accompanied by a major reduction in hardware mass. A prime example is the gas generator pump-fed engine cycle. Other possibilities include less hazardous propellants which permit thinner tank walls, or propellants that don't need tank insulation (e.g. alcohol).

Figure 2 is additionally useful for understanding the theoretical limits on payload. Given massless propulsion hardware (one stage by definition), the distance above the upper curve shows that $12 \%$ of the launch mass may be returned to earth, at Isp=315 s. The second curve shows that a maximum of twice this fraction could be placed in Mars orbit.

Understanding the problem in more detail requires breaking the non-propellant mass into payload and stage hardware. The entire mass of upper stages must be treated as payload for lower stages. Such staging analyses were performed by algebraic manipulation of mass ratios, and their sums and differences, starting with the rocket equation's ratios for the various propulsive burns. Specific impulse was assumed to be $315 \mathrm{~s}$, and all stages of multistage vehicles were assumed to have equal propellant fractions and $\Delta \mathrm{v}$.

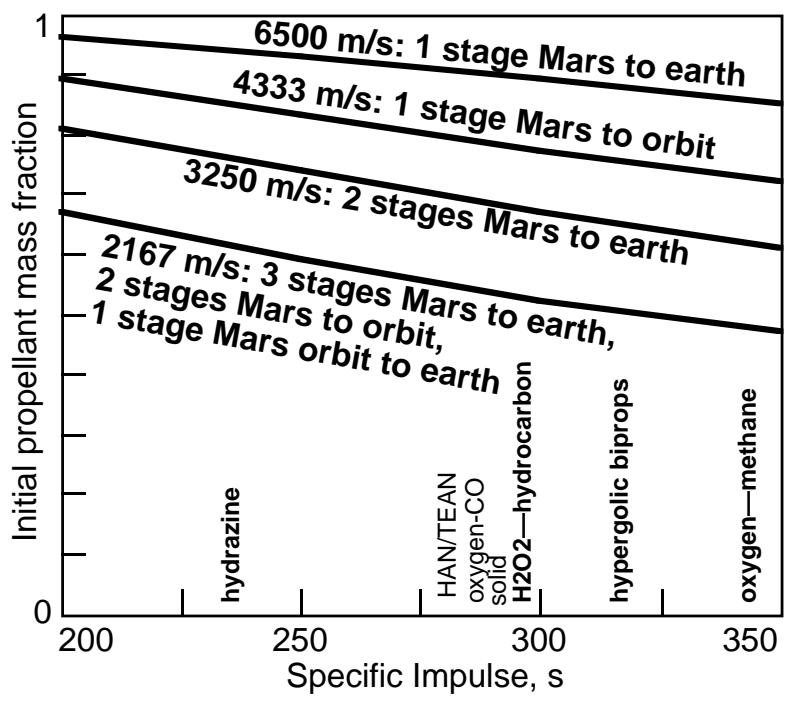

Figure 2. Stage propellant mass as a fraction of total remaining vehicle mass, for indicated maneuvers.

\section{Direct return staging analysis}

The fraction of launch mass which can be placed in an earthbound trajectory is represented by the heavy lines in Figure 3, for different staging options. The horizontal axis is the ratio of propellant mass in each stage to total mass (propellant and non-payload hardware) in that stage. For example, the right edge of the graph represents massless stage hardware, where staging becomes irrelevant and the payload fraction curves converge to the $12 \%$ limit noted previously. For real hardware, the heavy curves show that multi-stage vehicles deliver a higher payload fraction.

The thin lines in Figure 3 represent the fraction of launch mass which is available for the hardware of the uppermost

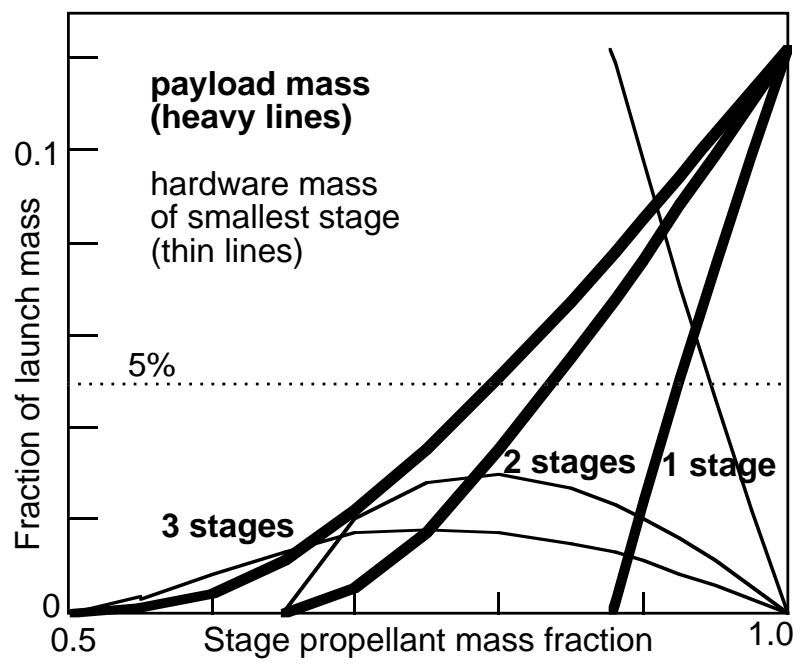


Figure 3. Mars to earth staging, $I s p=315 s, 6500$ $\mathrm{m} / \mathrm{s}$.

stage. These curves indicate that there is a disadvantage of increasing stage count with a fixed launch mass, namely that the uppermost stage gets smaller. As propellant fraction falls to the zero payload points, the upper stages vanish, because the first stage grows to consume the entire mass budget. The single-stage vehicle does not have this miniaturization effect, as the graph dramatically shows.

As a particular example of interpreting Figure 3, consider the goal noted in the Introduction, sending $50 \mathrm{~kg}$ toward earth with a launch mass of $1000 \mathrm{~kg}$. The $5 \%$ payload fraction is represented by the dotted line. For a single stage vehicle, the $950 \mathrm{~kg}$ stage would be $92.5 \%$ propellant (abscissa) and $7.5 \%$ inert (thin line ordinate). The empty stage mass is therefore $71 \mathrm{~kg}$.

Similarly, each of two stages would need to be only $84 \%$ propellant for the same 5\% payload, but the upper stage hardware would have to be miniaturized to only $28 \mathrm{~kg}$. A 3 -stage vehicle would relax the stage fraction requirement, but the smallest of these $80 \%$ stages would need to be built with less than $20 \mathrm{~kg}$ total hardware. This mass budget includes propulsion, structure, staging hardware, power, guidance, and other subsystems.

\section{Orbital rendezvous staging analysis}

Mars orbit rendezvous eases the maneuvering challenge for the Mars ascent vehicle. In Figure 4, the vertical scale has twice the range as in Figure 3. Payload fractions over 10\% are possible with stage propellant fractions above $75 \%$. A single stage Mars ascent vehicle also appears feasible.

The payload for this option would include little more than rendezvous aids (beacon and gravity gradient boom to null rotations) in addition to the sample itself, at perhaps $10 \mathrm{~kg}$ total. A 10\% payload fraction would be consistent with a $100 \mathrm{~kg}$ launch mass limit. ${ }^{1}$ If landing and sample collection hardware can be lightened (no rover), this could grow to a $25 \mathrm{~kg}$ payload within $250 \mathrm{~kg}$ at launch. The required stage fractions would be $84 \%$ (single) and $74 \%$ (2-stage). An upper stage for the $100 \mathrm{~kg}$ vehicle would have a hardware limit below $6 \mathrm{~kg}$.

\section{Staging analysis summary}

Figures 5 and 6 graphically display stage masses and propellant fractions, for the specific examples noted above. Also included is the possibility of one stage to Mars orbit and a second stage for return to earth (Figure 5D). For this latter option, the first stage is assumed to be $90 \%$ usable propellant $(754 \mathrm{~kg} / 838 \mathrm{~kg})$, which requires only a $73 \%$ propellant fraction $(82 \mathrm{~kg} / 112 \mathrm{~kg})$ for the upper stage. The unequal $\Delta \mathrm{v}$ split eases the propellant fraction for the smaller stage, but the first stage requirement is very close to that for a single stage vehicle.

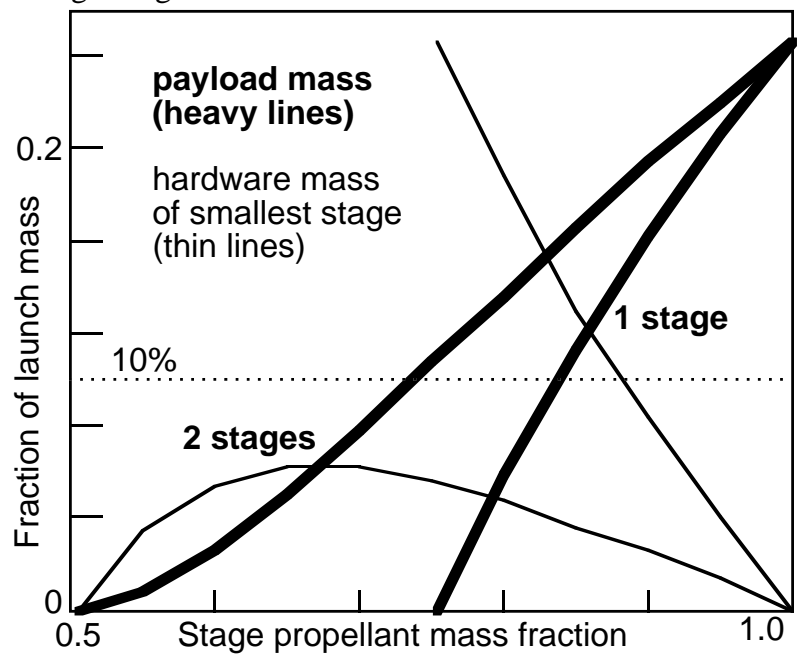

Figure 4. Mars to orbit staging, Isp=315 s, $4333 \mathrm{~m} / \mathrm{s}$.

Figure 6 additionally shows the two stages of a $100 \mathrm{~kg}$ vehicle which carries $10 \mathrm{~kg}$ to Mars orbit using only hydrazine. The full stages would mass $68.4 \mathrm{~kg}$ and 21.6 $\mathrm{kg}$, just as for the corresponding bipropellant case. Stage propellant fractions would need to be over $90 \%$.

If contours of constant engineering difficulty could be plotted in Figure 6, they would generally run from the lower left to the upper right. The notable result is that all the bipropellant stages fall in a band which runs in this general direction. The effort required is therefore insensitive to the mission scenario and the number of stages. For multi-stage options, the $\Delta v$ split should be biased slightly toward the larger stage(s) to follow the "difficulty contours."

\section{$50 \mathrm{~kg}$ spacecraft to earth}

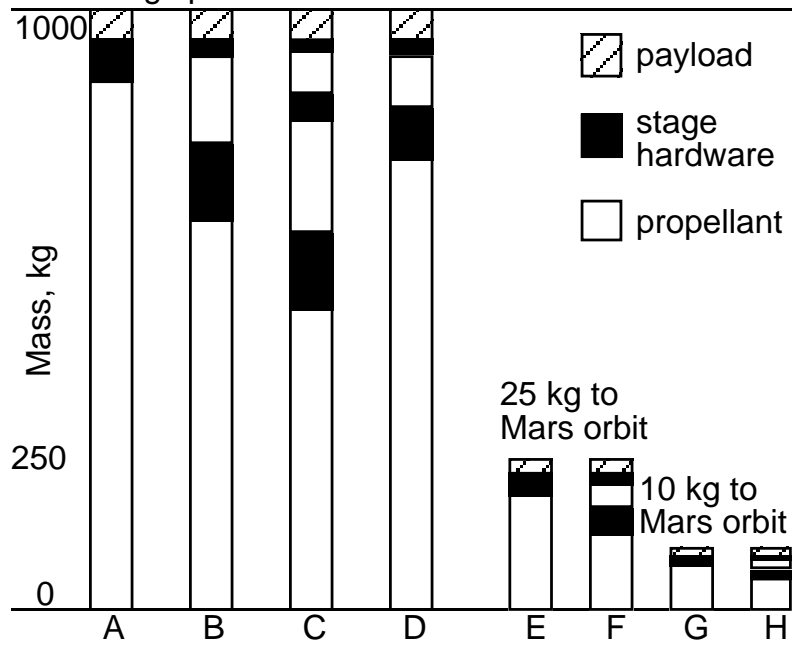


Figure 5. Vehicle mass breakdowns for staging options at Isp $=315 \mathrm{~s}$. All cases have equal $\Delta v$ splits, except case D which stages in Mars orbit.

X $1000 \mathrm{~kg}$ launch mass, $50 \mathrm{~kg}$ to earth, incl. cruise, course correction, \& recovery capability $(I s p=315 \mathrm{~s})$

O $1000 \mathrm{~kg}$ launch mass, $50 \mathrm{~kg}$ to earth, 2-stage unequal $\Delta v$ split with staging in Mars orbit (Isp $=315 \mathrm{~s})$

+ $250 \mathrm{~kg}$ launch mass, $25 \mathrm{~kg}$ to Mars orbit, incl. rendezvous functions (Isp $=315 \mathrm{~s}$ )

* $100 \mathrm{~kg}$ launch mass, $10 \mathrm{~kg}$ to Mars orbit, incl. rendezvous functions ( $\mathrm{Isp}=315 \mathrm{~s}$ )

$100 \mathrm{~kg}$ launch, $10 \mathrm{~kg}$ to Mars orbit (Isp=230 s)

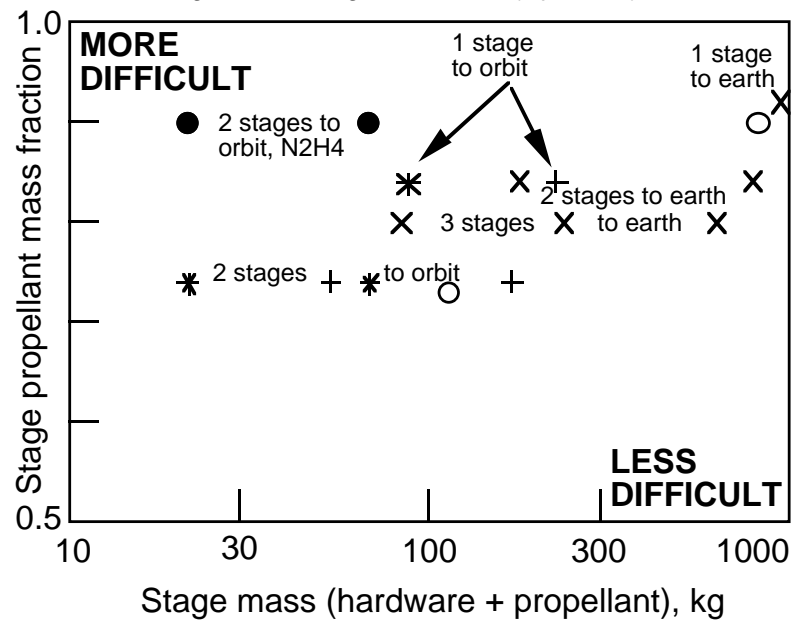

Figure 6. Propellant fractions vs. stage size.

In summary, Figures 5 and 6 are primarily intended to focus attention on the trade between extreme propellant fractions and extreme miniaturization. The only assumptions are $\Delta v^{\prime} s$, specific impulses, launch masses, and payload masses. Small variations from these assumptions do not change the result. Namely, no option for staging or mission scenario dramatically eases the need to build tiny rocket stages having high propellant fractions.

\section{$\underline{\text { Small propulsion systems }}$}

The logical next step is to compare the requirements to current capabilities. Spaceworthy and experimental propulsion systems are plotted in Figure 7. The axes and scales are the same as in Figure 6, which permits a direct comparison. The examples shown are the best demonstrated systems known to the author, in terms of achieving both miniaturization and high propellant fraction. As discussed below, all the examples in Figure 7 fall short of meeting Mars ascent requirements, for a variety of reasons.

\section{Solid motors and stages}

A quick glance at Figure 7 suggests that existing solid rocket motors are ideal for Mars ascent. The reduced specific impulse of solids has only a minor effect. If
Figure 6 is plotted for Isp=287 s, propellant fraction requirements would rise by just a few percent.

Solid motors, no directional control (Isp = $287 \mathrm{~s}$ ), high thrust/weight $>15$, high control torques needed

Advanced Solid Axial Stage (ASAS), a solid motor with directional control subsystems (Isp = $287 \mathrm{~s}$ )

Near Earth Asteroid Rendezvous propulsion

$\square$ system as flown, low thrust/weight $=0.12($ Isp=315 s)

由 Clementine I propulsion without structure

$\boxplus$ as flown, low thrust/weight $=0.20($ Isp=315 s)

- LLNL experimental pump-fed propulsion (Isp = $230 \mathrm{~s}$ )

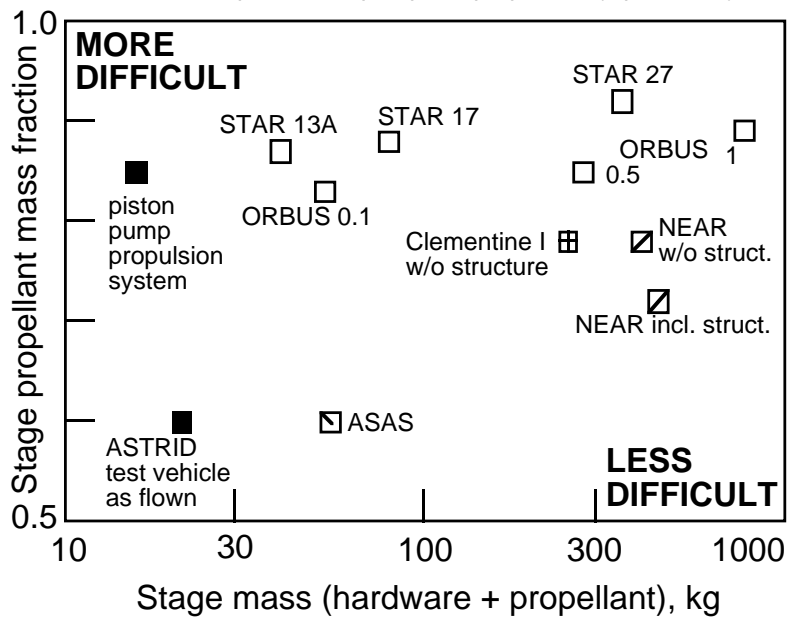

Figure 7. Propellant fraction and stage sizes for small rocket motors and propulsion systems.

One early study found solids to be superior to liquids for Mars launch. ${ }^{6}$ Solids naturally have high thrust so there is no extra penalty for engine mass. However, the paper did not offer hardware details.

The real problem is that solid motors cannot be used alone as Mars ascent stages, because they lack directional control capability. This is not a minor detail, since high control torques are required by the intrinsically high thrust of solid motors, multiplied by variations in the thrust direction and mass center. Also, a rapid and precise control system is needed, since the high acceleration of solid rockets increases the effect of any trajectory errors.

Spinning during operation has been widely used for directional control of solid motors in space, and liquid systems are always subsequently used for orbit adjustments. This or any other method of control requires extra mass. Figure 7 includes one recent flight test example, which falls short of Mars ascent requirements. The Advanced Solid Axial Stage was developed by the USAF and Thiokol ${ }^{7}$. Its 55-kg flight-ready mass included $33 \mathrm{~kg}$ of propellant and $>10 \mathrm{~kg}$ for thrust vector and attitude control subsystems. 
A major advantage of solid propellant is that it can't freeze. Another consideration regarding solid rockets is that they are the least compatible with currently-envisioned in-situ propellant scenarios. Hybrid rockets having a solid fuel and liquid oxidizer are a possibility, especially since oxygen is the easiest propellant to obtain on Mars.

Spacecraft liquid systems

Bipropellant propulsion systems which have recently flown on the Near Earth Asteroid Rendezvous (NEAR) and Clementine I programs are prime examples of the state of the art in the mass range of interest. These are the smallestscale deep space missions having significant maneuvering capability $(>1 \mathrm{~km} / \mathrm{s})$.

A direct comparison of Figures 6 and 7 indicates that the existing bipropellant systems are too large to meet upper stage needs. Also, the most optimistic points have slightly lower propellant fractions than required for the Mars ascent stages of their own size.

Figure 8 shows the detailed mass breakdowns for the bestcase bipropellant points plotted in Figure 7. These optimistic numbers are based on propulsion component mass lists. ${ }^{8 \& 9}$ Structure and other stage hardware (e.g. electrical power and guidance) are not included. In addition, the thrust levels on both systems are much too low to lift off of Mars.

The NEAR propulsion system had its own $33 \mathrm{~kg}$ structure, separate from the spacecraft bus. Clementine I had about $50 \mathrm{~kg}$ of structure. In either case, the propulsion system's share of structural mass roughly equals the total tank mass. This reduces the propellant fraction to the neighborhood of $70 \%$.

If structure is assumed to be massless, and enough extra engines are added to either propulsion system to lift off of Mars, the propellant fraction would also fall to approximately $70 \%$.

Assuming that these deep space missions would have used lighter weight hardware had it been available, one can conclude that conventional spacecraft bipropellant technology is not capable of meeting Mars ascent requirements. Not only does structural mass need to be eliminated, but the wet propulsion hardware must be lighter as well. In addition to the need for more and lighter engines, a glance at Figure 8 suggests a reduction in tank mass would be valuable.

\section{Missile defense liquid systems}

Several test articles developed over the past decade have made impressive advances toward very small size $(\sim 10 \mathrm{~kg})$ and high acceleration (multiple earth g). ${ }^{10}$ In order to reach these extremes, propulsion engineers sacrificed operating
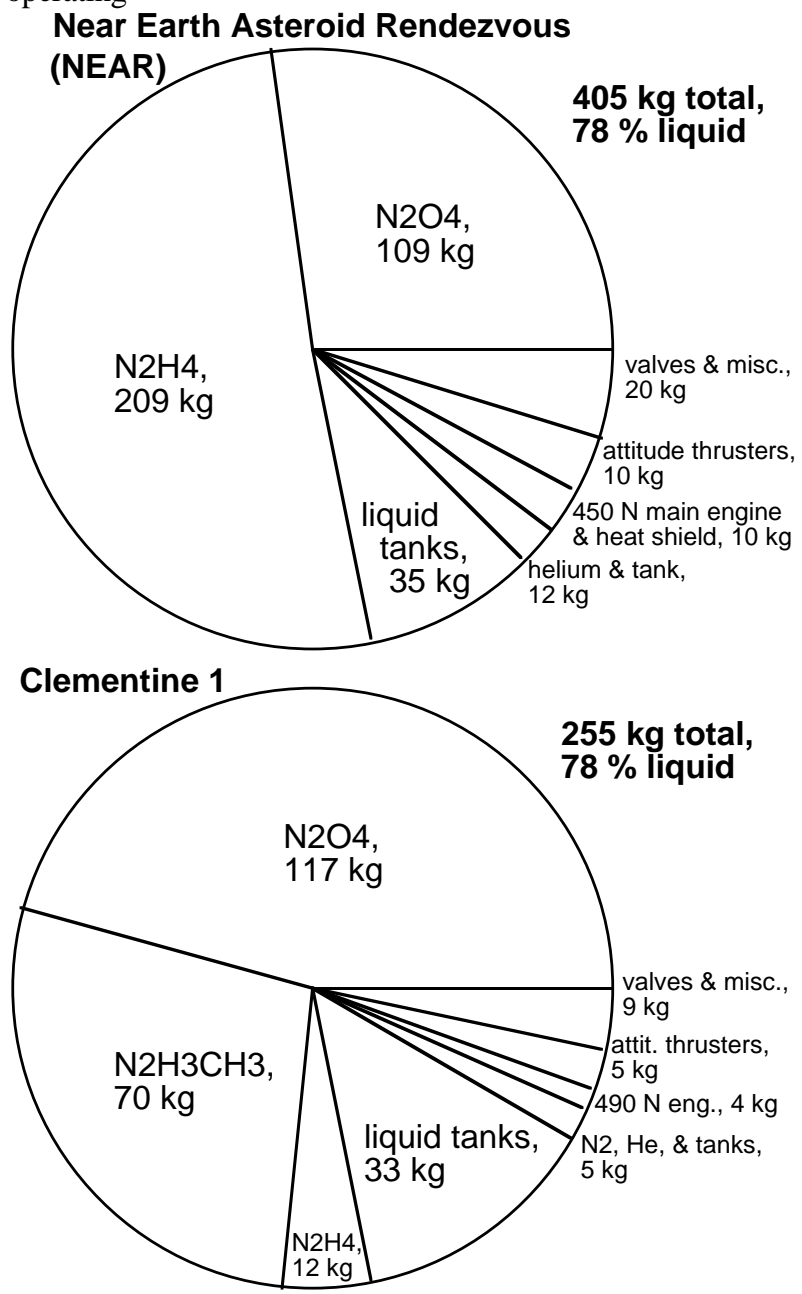

Figure 8. Propulsion mass breakdowns for recent small spacecraft. Structural mass is omitted here.

lifetime and propellant fraction. The former may be consistent with Mars ascent. The latter is unacceptable, considering that these tiny propulsion systems fall below the bottom of the scale in Figure 7. The primary reason is that relatively heavy tanks for both gas and propellants were used to provide high feed pressures.

The high pressure systems do have the right attributes to perform Mars landings on a tiny scale. ${ }^{10 \& 11}$ Since most of the deceleration is done with the aid of Mars' atmosphere, this high acceleration maneuver requires only a very low $\Delta \mathrm{v}$ (Figure 1).

Missile defense developments include the use of warm gas pressurization. Eliminating pressurant tanks mitigates storage safety hazards. However, liquid tank mass may be 
increased, to operate at elevated temperatures and isolate incompatible fluids from one another.

The author's test system appears on the left side of Figure 7 along with its ASTRID flight experiment vehicle. ${ }^{5}$ The latter had a thrust/mass ratio more than twice that required for Mars ascent. Miniature pumps were used in combination with low pressure tanks and high pressure thrusters, to enable both high propellant fractions and high acceleration. The demand-responsive pumps permitted offpulsing among the four main thrust chambers, for inherent directional control capability. This promising technology needs further dedicated development, especially to operate with bipropellants.

\section{$\underline{\text { Propulsion components }}$}

Missile defense research also resulted in significant miniaturization of valves, partly because these feed system components can be lightweighted for short-life applications (e.g. leakage is less critical). The fundamental limit on system hardware mass equals the mass sum of components which carry propellant or deliver thrust, the two primary functions of propulsion hardware. For propellant fractions near $80 \%$ that are of interest to Mars ascent, a reasonable goal is to limit tanks and engines each to $5 \%$ of the wet stage mass.

\section{Propellant tank technology}

Given a liquid density, the tank mass-to-volume ratio determines a stage's tankage fraction relative to its propellant fraction. The density of water (similar to that of propellants) was used to plot normalized tank mass as a function of scale, in Figure 9.

The left half of the graph is relevant to $1000 \mathrm{~kg}$ Mars-toearth vehicles, but only the leftmost quarter shows tanks small enough for direct return upper stages and small Marsto-orbit flights. The clear indication is that tanks become relatively heavier as they are scaled down, and the smallest ones can be far heavier than the $5 \%$ goal.

Note in Figure 9 that the normalized mass of the Centaur tanks is only $1 \% .^{12}$ This number is typical of many other launch vehicle tanks operated near $0.35 \mathrm{MPa}$ (50 psi). ${ }^{4}$ In contrast, large spacecraft typically allocate $\sim 3 \%$ of their propellant mass to spherical titanium liquid tanks, as indicated by the HS-601 example. ${ }^{13}$ The threefold mass increase relative to launch vehicle tanks results from a $>5 \mathrm{x}$ higher pressure, mitigated by the superior shape and material.

If pressure and material properties are constant, tanks can theoretically scale along horizontal lines in Figure 9. ${ }^{14}$ In practice, the design and fabrication of tanks needed for small Mars return stages is severely constrained by safety rules governing minimum wall thickness.

A curve representing ideal spherical titanium tanks having 1 $\mathrm{mm}$ thick walls is included as a rough guide to appreciating the above point. The smallest spacecraft tanks (e.g. Clementine) are heavier still, due to internal diaphragms for propellant management. However, the NEAR oxidizer $\operatorname{tank}^{15}$ can be fairly compared to that flown on Hughes' HS-601 satellite bus. Both are titanium spheres having only minimal propellant management devices.

Low pressure safety factors (1.5-2.0) used for spacecraft require fracture mechanics criteria to be satisfied. Essentially, it is necessary to assume that a tank wall contains undetectable cracks up to $0.5 \mathrm{~mm}$ (.02 inch) deep. ${ }^{16}$ Neither standard inspection techniques nor proof test pressures consistent with low safety factors can guarantee detection of these flaws.

A possible alternative approach to ensuring safety with thinner tank walls is to limit operating pressure to a smaller fraction of proof pressure. This vastly diminishes the likelihood that tanks will rupture due to cracks that are not quite deep enough to cause rupture during proof testing.

Just below the 5\% line at the smallest size, Figure 9 includes the low pressure hydrazine tank designed and fabricated at LLNL for the miniature pump-fed sounding rocket experiment. ${ }^{5}$ The $152 \mathrm{~mm}$ (6 inch) diameter cylindrical section of this 15.3 liter tank was made of Ti6Al4V sheet, only $0.2 \mathrm{~mm}$ (.008 inch) thick. Proof testing was at twice the maximum operating pressure of $0.85 \mathrm{MPa}$, and the burst safety factor was nearly 4. Design qualification included 200 pressure cycles to $1.4 \mathrm{MPa}$, and vibration testing at $10 \mathrm{~g}$ RMS for $100 \mathrm{~s}$. The $0.73 \mathrm{~kg}$ mass includes heavy end flanges and conduits through the tank.

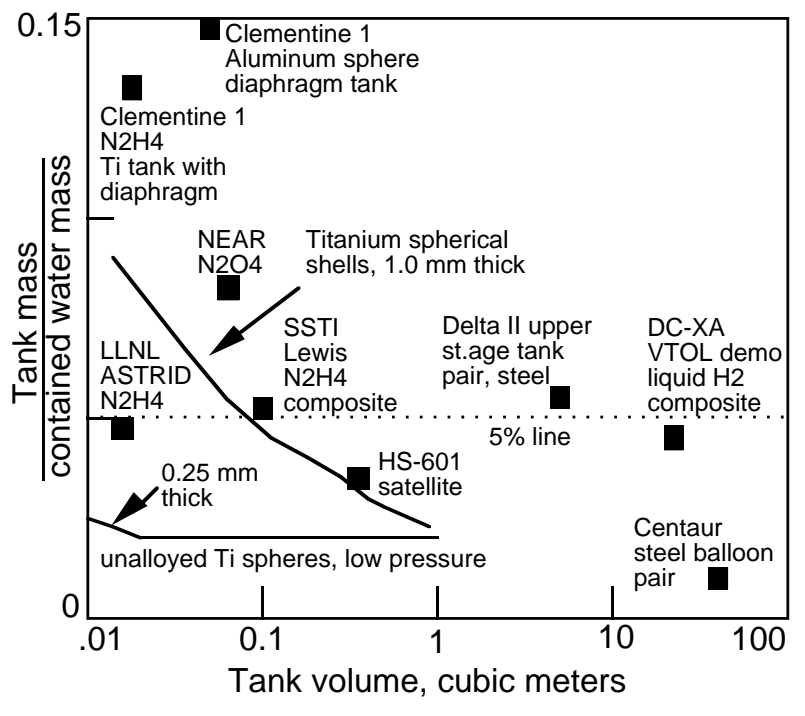


Figure 9. Tank performance over the range of interest.

The lower curve in Figure 9 suggests what is possible by utilizing a similar approach for spherical tanks. For low pressures, lower-strength commercially pure titanium can be used to facilitate forming hemispheres from sheet. The horizontal part of the curve at $2 \%$ represents tanks which operate at $0.35 \mathrm{MPa}$, with a burst safety factor of 4 (at $\geq 470 \mathrm{MPa}$ strength). Below 20 liters, the normalized mass would rise given an arbitrary minimum wall thickness of $0.25 \mathrm{~mm}$. Such low-pressure sheet metal tanks would enable even the smallest stages contemplated in Figures 5 and 6, but pump-fed engines would be needed to avoid excessive thrust chamber size and mass.

Composite materials based on high strength carbon fibers can theoretically enable lighter tanks. The primary application has been to gas pressure vessels having relatively thick walls. Their performance criteria is $\mathrm{PV} / \mathrm{W}$ (pressure $\mathrm{x}$ volume/weight), whereas V/W matters most for incompressible fluids. Two examples of composite liquid tanks are included in Figure 9. The DC-XA liquid hydrogen tank was designed to feed the Centaur engine (RL-10) and to carry a similar volume. Clearly, the use of advanced materials alone does not necessarily reduce mass.

Of greater interest for Mars return is the 96 liter hydrazine tank which is part of the SSTI Lewis spacecraft scheduled for launch in 1997. Although its operating pressure capability is above $3 \mathrm{MPa}$, Figure 9 shows that its liquidcarrying capacity is similar to that of conventional titanium tanks. ${ }^{17}$ The difficulty is in fabricating and qualifying thin walls having very few composite layers as well as a leaktight liner. For example, numerous liter-scale fiberwound liquid tanks have been developed for missile defense, but achievable mass has been a large fraction of propellant mass.

In summary, there are several possible routes to lighter tanks. These include improved methods for crack detection or higher safety factors to permit thinner walls, as well as potential advances with composites. Safety standards may need to be updated before such new tanks can be filled with propellants at earth launch ranges. A possible alternative is to launch tanks empty from earth then fill en route or on Mars, if criteria for mission success are less stringent than for human safety. Perhaps nontoxic propellants can help to ensure safety with thinner tank walls. Consider that the common aluminum beverage can has a $0.1 \mathrm{~mm}(.004 \mathrm{inch})$ wall and bursts at $1 \mathrm{MPa}$. If Figure 9 were extended two orders of magnitude to the left, the can would appear at $4 \%$ on the vertical axis, including its thick ends.
It can be argued that the use of tanks heavier than 5\% of the propellant would not by itself prevent building stages having propellant fractions near $80 \%$. However, the above discussion ignored gas pressurant tanks, as well as insulation and structure associated with tanks.

\section{Rocket engine technology}

Conventional rocket engines are even more likely than tanks to demand an excessive share of the mass budget. From Figure 1, a thrust-to-mass ratio similar to earth's surface gravity is desired for an efficient departure from Mars. The earth weight of engines would need to be $<5 \%$ of thrust, to avoid exceeding a 5\% fraction of stage wet mass.

Figure 10 shows that weight/thrust ratios vary widely for small liquid rocket engines (note vertical log scale). The highest thrust levels shown are needed to lift $\sim 1000 \mathrm{~kg}$ off of Mars. Thrusts near the left edge of the graph are needed for attitude control. Comparing the two points at $5 \mathrm{~N}$ thrust strongly suggests that warm gas jets should be used for weight critical applications.

Conventional engines used on spacecraft react hypergolic bipropellants or hydrazine fed at up to $\sim 3 \mathrm{MPa}$. These are generally relatively heavy, except at the highest thrust levels. Each point plotted below $1000 \mathrm{~N}$ and above the 5\% line represents products from several manufacturers in this highly competitive market. For example, there are roughly 5 sources throughout the world for the bipropellant apogee engine that is widely used to circularize satellites into geostationary earth orbit. Three sources for this engine are represented on NEAR, Clementine I, and Galileo.

The fact that exploration programs usually use propulsion components which serve commercial markets hints at the difficulty of obtaining Mars ascent engines. In particular, engine weight is a low priority for the apogee maneuver, 


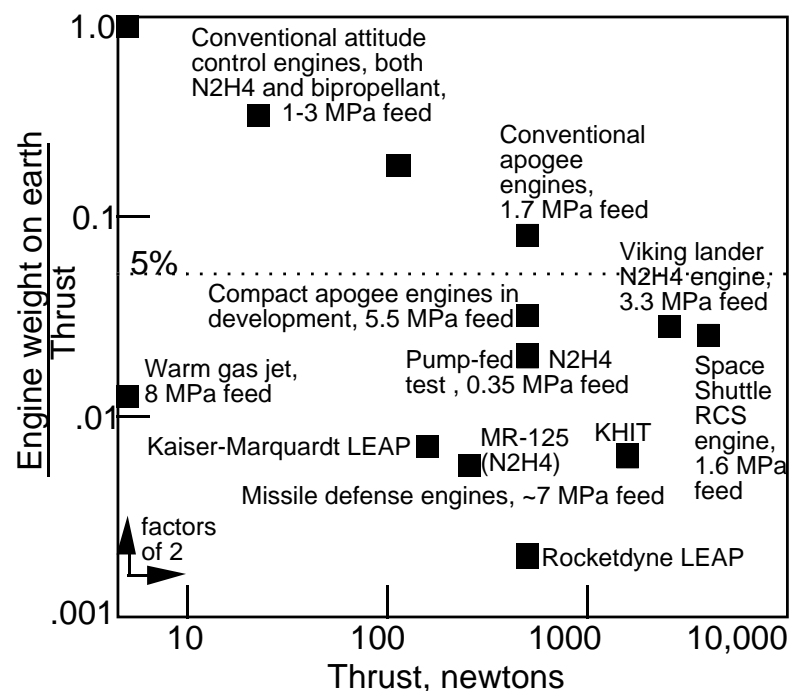

Figure 10. Rocket engine weight/thrust ratios.

shown in the lower left corner of Figure 1. Instead, the competitors strive to increase specific impulse by individual percentage points, to increase market share. This enhances payload delivery to GEO, but small Isp changes are insignificant compared to hardware weight for Mars ascent.

Several companies have been funded by NASA to develop compact apogee engines at the same $490 \mathrm{~N}(110 \mathrm{lb})$ thrust level. ${ }^{18-20}$ Their goals include increasing Isp and roughly halving the conventional $\sim 0.5$ meter lengths to package smaller satellites on smaller launch vehicles. It is expected that long-life engines will be available below the 5\% weight goal as indicated in Figure 10. However, there is a $\sim 5 \mathrm{x}$ increase in chamber pressure over conventional apogee engines, which requires feed pressures above $5 \mathrm{MPa}$. The engine development papers referenced above do not specifically address tank mass.

The lower third of Figure 10 includes missile defense thrusters which are even smaller and lighter, by virtue of having not only higher feed pressures, but reduced operating lifetimes that may be too short for Mars ascent. ${ }^{10}$ An exception is the high pressure monopropellant hydrazine thruster (RRC MR-125). One flightweight test article was operated in vacuum for $1000 \mathrm{~s}$, including 10 minutes continuously. ${ }^{21}$

Several MR-125 thrusters were also operated with a pump assembly and its warm gas drive circuit. $5 \& 22 \& 23$ The pump and gas generator hardware raised weight to $2 \%$ of thrust as plotted in Figure 10. The benefit of this increase was to cut feed pressure by a factor of 20 . To date, this pump technology has been successfully implemented only with monopropellant, which has the obvious drawback of low Isp.
The main conclusion to be drawn from Figure 10 is that new rocket engines must be developed to meet the $5 \%$ goal for Mars ascent, if conventional propellants are used. This statement is obviously also true in the cases of nontoxic and/or in situ propellants, since no flightweight engines are available for these options. For any propellant combination selected, sufficiently lightweight and compact thrust chambers will require feed pressures above the standard which has evolved for low-acceleration orbital maneuvers.

\section{Summary of existing technology vs. needs}

It generally appears that available rocket technologies do not meet the need. As a final test, several outlying examples are considered here.

The most striking point made by Figures 9 and 10 is that the effect of scale is tremendous over the range of interest. This suggests the attempt of a single-stage-to-earth design that avoids miniaturization. The component data graphs indicate that a $1000 \mathrm{~kg}$ stage could be assembled using 3\% liquid tankage and 3\% engines. Figure 6 requires that such a stage be $92.5 \%$ propellant, which leaves only $1.5 \%$ of the mass budget for pressurant tanks, valves, plumbing, heaters, insulation, structure, attitude control, residual fluids, etc.

The above prospect seems untenable, but perhaps a first stage of a Mars-to-earth vehicle could be implemented using modified conventional technology. ${ }^{24}$ A similar $1000-\mathrm{kg}$ stage (at $>80 \%$ propellant fraction) could reach Mars orbit. This option would fit the affordability criteria, only if a complete empty vehicle plus propellant production apparatus could be sent to Mars on a Delta II class mission.

One point not mentioned previously is that upper stages require lower acceleration than needed for launch. If upper stage thrust can be reduced by a factor of 2, for example, the 5\% ceiling in Figure 10 could be raised to $10 \%$. Conventional hardware below $\sim 300 \mathrm{~N}$ thrust would still be too heavy, but off-the-shelf apogee engines may seem promising for a large upper stage. This is still beyond existing technology, per the discussion of Figure 8.

The opposite extreme is to accept miniaturization, but strive for lower propellant fractions. Such an outlying case is the largest Mars-to-orbit vehicle at $250 \mathrm{~kg}$, with a minimum 10 $\mathrm{kg}$ payload. Returning to Figure 4, a pair of $63 \%$ stages would accommodate the $4 \%$ payload. The low propellant fraction would bring the $40 \mathrm{~kg}$ upper stage closer to, but not within, proven missile-defense propulsion capabilities. 
This paper has reviewed the key aspects of the Mars ascent problem and consolidated some critical details. One indication is that small-scale propulsion technology must move forward in large steps, in order to bring Mars samples home. The analysis also suggests that technology developments can proceed before decisions are made about mission scenario or stage count. As long as the smallest stage sizes and highest propellant fractions are set as goals, new advances will be relevant.

\section{$\underline{\text { Launch vehicle design principles }}$}

Earth-to-orbit launch vehicle stages use propellants having a high specific impulse, along with extremely lightweight hardware. Design principles include the use of tank walls (or the motor case) as vehicle structure, and effecting directional control with the main nozzles when possible. Additionally, carrying significant amounts of stored gas is avoided.

Liquid stages operate thrust chambers above $3 \mathrm{MPa}$ to minimize engine size and weight, as well as to increase Isp. Simultaneously, tanks run at low pressure $(\sim 0.3 \mathrm{MPa})$ to minimize tank and pressurant weight. This mode of operation requires pumps for propellant delivery. It is acknowledged that rocket engine pumps and their warm gas power systems are complicated, expensive, and subject to poor reliability. These drawbacks prove they are essential, since they would otherwise be abandoned in short order. Falling back to pressure fed operation only compromises tank mass, engine mass, or both.

Large engines weigh $<2 \%$ of their thrust level, including pumps, turbines, gas generators, control valves, and complicated plumbing. The typical $1 \%$ tankage fraction noted previously rises only as high as $3 \%$, when lowdensity hydrogen is the fuel. Techniques which minimize non-tankage structure include the use of common bulkheads between fuel and oxidizer.

Each of the launch vehicle design principles noted here contributes to reducing hardware mass, and the result is striking when all are implemented in combination. Stage propellant fractions well above $90 \%$ are routinely obtained. Interestingly, spacecraft propulsion systems typically violate all these principles. Perhaps it is a valuable step just to recognize that Mars departure requires a launch vehicle, not a spacecraft.

\section{Ascent vehicle configuration}

Non-propulsion mass can contribute significantly to stage inert mass, so eliminating structure is of similar value to using pump-fed engines. Figure 11 compares a spacecraft tankage configuration to an alternative based on launch vehicle design principles. The common bulkhead design within a spheroid instead of a tall cylinder is consistent with the low ascent drag in Mars' thin atmosphere.

Theoretically, the common bulkhead is excess mass because it carries no pressure load. However, the benefit is to eliminate structural members as shown. If tank wall thickness is restricted to an absolute dimension as expected, then the total area determines mass. For equal propellant volumes, the lower sketch has 1.6 times the tank radius, but $17 \%$ less area, including the common bulkhead.

It is acknowledged that a common bulkhead with no vented space between hypergolic propellants is taboo in spacecraft safety culture. At the same time, it is notable that the current series of Mars missions uses precisely this design. The Delta II upper stage tank (Fig 9) carries over 5 tons of monomethyl hydrazine and nitrogen tetroxide at $1.6 \mathrm{MPa}$, separated only by a sheet of stainless steel. ${ }^{25}$

A critical problem is that of insulating the propellants. Wind at $200 \mathrm{~K}$ on Mars presents a worse thermal environment than space. The unitized design in Figure 11 permits a $37 \%$ reduction in tank surface insulation.

The multiple engines required in the lower sketch may be fed directly by short tubes from the upper propellant container. If they can be throttled or pulsed with adequate precision, pitch/yaw control is intrinsic. Although a single center engine can fit the four-tank configuration, extra thrusters or a gimbal would still be needed for directional control. Also, plumbing from all four tank outlets is required.

\section{Packaging}

Arrival at Mars imposes constraints on the ascent vehicle's shape. The descent aeroshell shape is driven by the need to maximize the drag coefficient without sacrificing aerodynamic stability. Slowing down requires a ballistic coefficient of roughly $50 \mathrm{~kg} / \mathrm{m}^{2} .26$ While this provides plenty of aeroshell volume to carry the maximum mass at liquid propellant densities, the ascent stack cannot be tall.

In order to consider the worst-case packaging problem, the largest Mars-to-orbit vehicle (250 kg, 2-stage, Figure 5F) is compared in Figure 12 to an aeroshell of contemporary design. ${ }^{27}$ The first stage would have a $0.6 \mathrm{~m}$ diameter sphere, and $0.25 \mathrm{~m}$ engine length. The latter is based on using four to six compact apogee engines (Figure 10). Conventional apogee engines would be over twice as long, which seems unworkable in Figure 12. 


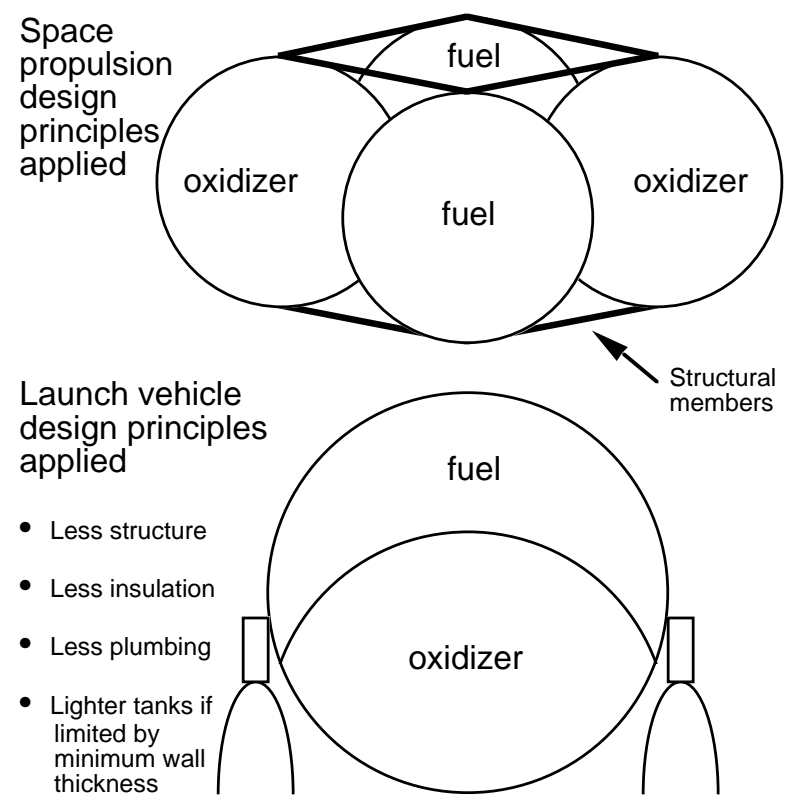

Figure 11. Packaging alternatives for a Mars ascent stage, scaled to represent equal tank volumes.

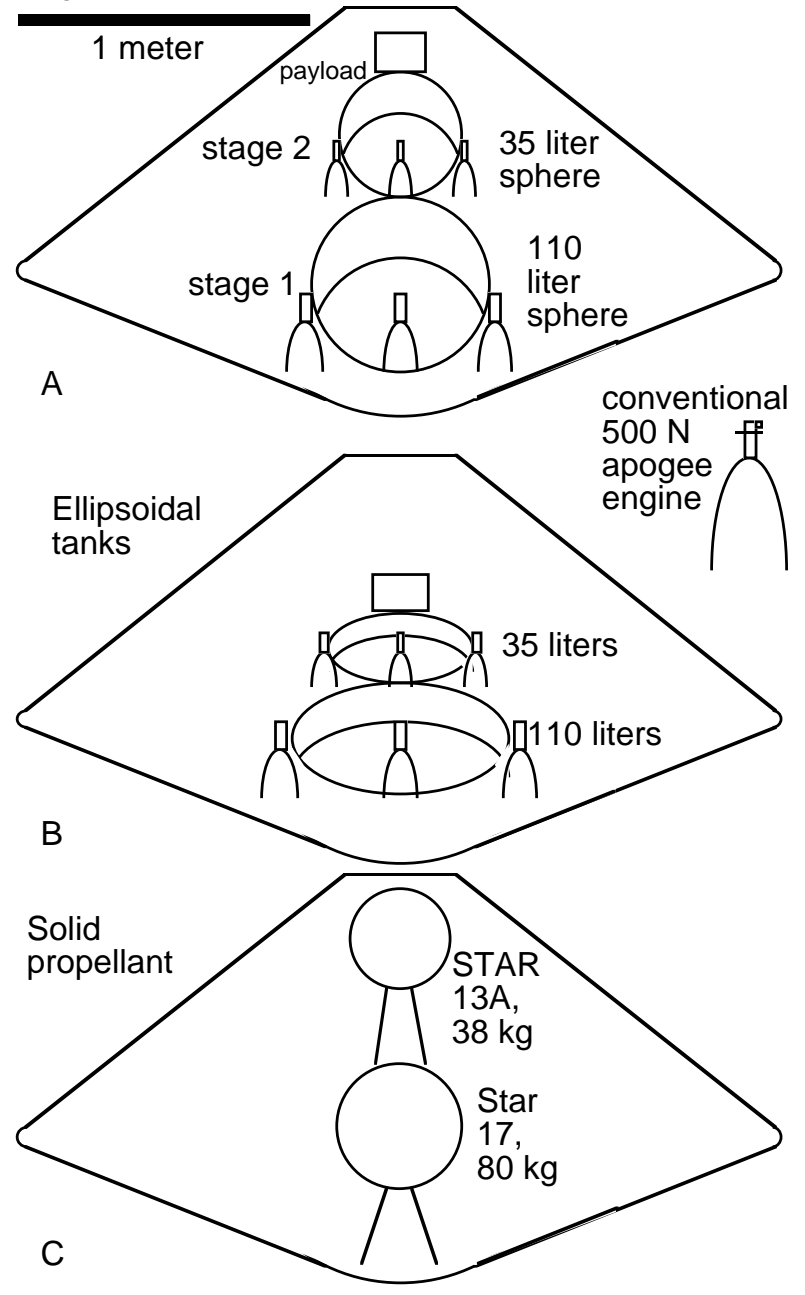

Figure 12. Two stage Mars-to-orbit vehicle options in Pathfinder aeroshell for arrival at Mars.

In Figure 12A, the full 2-stage vehicle just fits within the Pathfinder aeroshell. Oblate spheroids can also be used, as indicated in Figure 12B. The latter tank shape may be appropriate for a 3-stage Mars-to-earth vehicle (in a larger aeroshell).

Assuming low pressure sheet metal tanks, the 2:1 ellipsoids indicated in Figure 12B can be formed from a high-strength titanium alloy instead of pure titanium which permits forming hemispheres. Therefore, the less efficient shape is not necessarily heavier. If separate attitude control thrusters are required, the highly oblate spheroid increases their moment arms without requiring extra structure. A drawback of the oblate tank is an increase in residual propellant.

Clearly, a smaller $100 \mathrm{~kg}$ Mars-to-orbit vehicle would fit easily into the aeroshell, as would the single stage $250 \mathrm{~kg}$ option. A larger aeroshell would be required to land 1000 $\mathrm{kg}$ Mars ascent vehicles. If the latter are sent to Mars with empty tanks for in-situ propellant production, Figure 12 suggests that the aeroshell would be sized for the vehicle dimensions, rather than the mass. Such a larger aeroshell might reduce the mass benefit of local propellants.

In consideration of solid propellant, a stack of spherical stages similar to existing motors is the easiest configuration. Figure $12 \mathrm{C}$ shows that nozzle dimensions would restrict packaging. If the STAR 13A is stacked atop the STAR 17 , the $1.3 \mathrm{~m}$ tall combination would barely fit in the Pathfinder aeroshell. It would be a relatively low mass vehicle, given the motor sum of $120 \mathrm{~kg}$.

\section{Pump technology}

In addition to previous discussions of hardware mass, the above packaging considerations favor high pressure liquid rockets over both solids and conventional space engines. Small scale pumps are therefore of great interest.

Figure 13 shows that turbopump weight is less than a half percent of thrust, for large rocket engines. There is a slight trend toward increased weight as thrust falls from $10 \mathrm{MN}$ to below $0.1 \mathrm{MN} .28$ Few pump-fed engines have ever existed at lower thrust levels. They include the $16.7 \mathrm{kN}$ XLR-132, a recent development. ${ }^{29}$ This gas generator cycle engine is fed with hypergolic bipropellants. Its $23 \mathrm{~kg}$ flightweight pump ${ }^{30}$ is heavier than would be expected from simple extrapolation of the other turbopump data. 


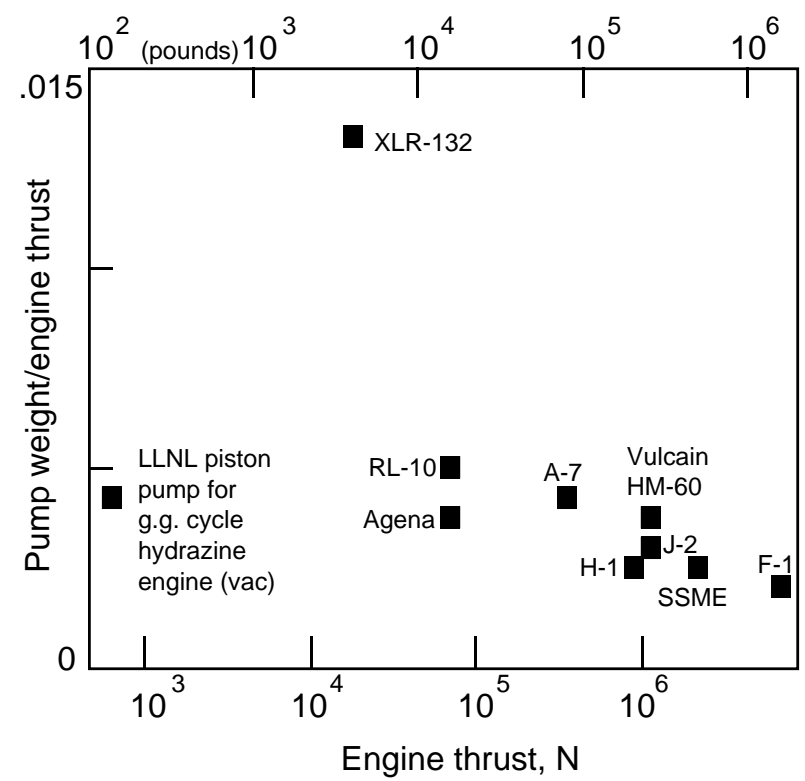

Figure 13. Historical rocket engine pump capabilities.

The XLR-132 turbopump is far from being unacceptably heavy, but the trend suggests that turbopumps for smaller engines might be impractical. Only the leftmost order of magnitude in Figure 13 is of interest for small scale Mars departure. As noted previously, reciprocating piston pumps have been demonstrated in the $250-750 \mathrm{~N}$ thrust range. The leftmost point in Figure 13 indicates it is fundamentally sound to consider reciprocating pumps for Mars launch vehicles. Even if mass doubles, it would be only $1 \%$ of gross stage mass, which is entirely consistent with propellant fractions as high as $90 \%$.

\section{Reciprocating pump designs}

The practical considerations for implementing reciprocating rocket engine pumps are many. Numerous design options include the choice of pistons, bellows, or diaphragms. Unique advantages include the fact that the speed of reciprocating pumps follows liquid demand. This feature permits thrust chamber pulsing or throttling down to zero, while the pumps remain responsive at full pressure. Applicability is not intrinsically limited to particular propellants, pressures, temperatures, materials, or engine cycles, but engineering is needed for new implementations.

Previous papers give detailed descriptions of piston pumps for hydrazine ${ }^{5}$ and bellows pumps for oxidizer. ${ }^{31}$ An unpublished proof-of-principle test at subcontractor KaiserMarquardt in 1994 demonstrated pump operation with bipropellants. Fatigue failure of the metal bellows which separated the hot hydrogen mixture from the nitrogen tetroxide would have been catastrophic. Also, it was undesirable to have entirely different pump designs for fuel and oxidizer.
The original hydrazine pump pair is sketched in Figure 14A (liquid check valves not shown). This configuration could only exhaust to ambient pressure because the refill stroke relied solely on tank pressure. Unwanted complexity included welded-on warm gas valves connected by the supply pipe and tiny pneumatic signal tubes (thick lines).

One new design, Figure 14B, places the drive cylinders of two pumping chambers back to back. ${ }^{32}$ The warm gas valves and pneumatic control mechanism are machined into the common cylinder head, which has a single port for the gas feed and one for exhaust. Two pistons are linked by a center rod, which permits powered refill down to the propellant's cavitation limit at the inlet check valves. More importantly, the exhaust gas can be expelled at above tank pressure. This new capability opens up the possibility of implementing expander cycle engines with reciprocating pumps. At a minimum, pump exhaust can be used for tank pressurization and to operate auxiliary thrust chambers so that useful impulse is obtained.

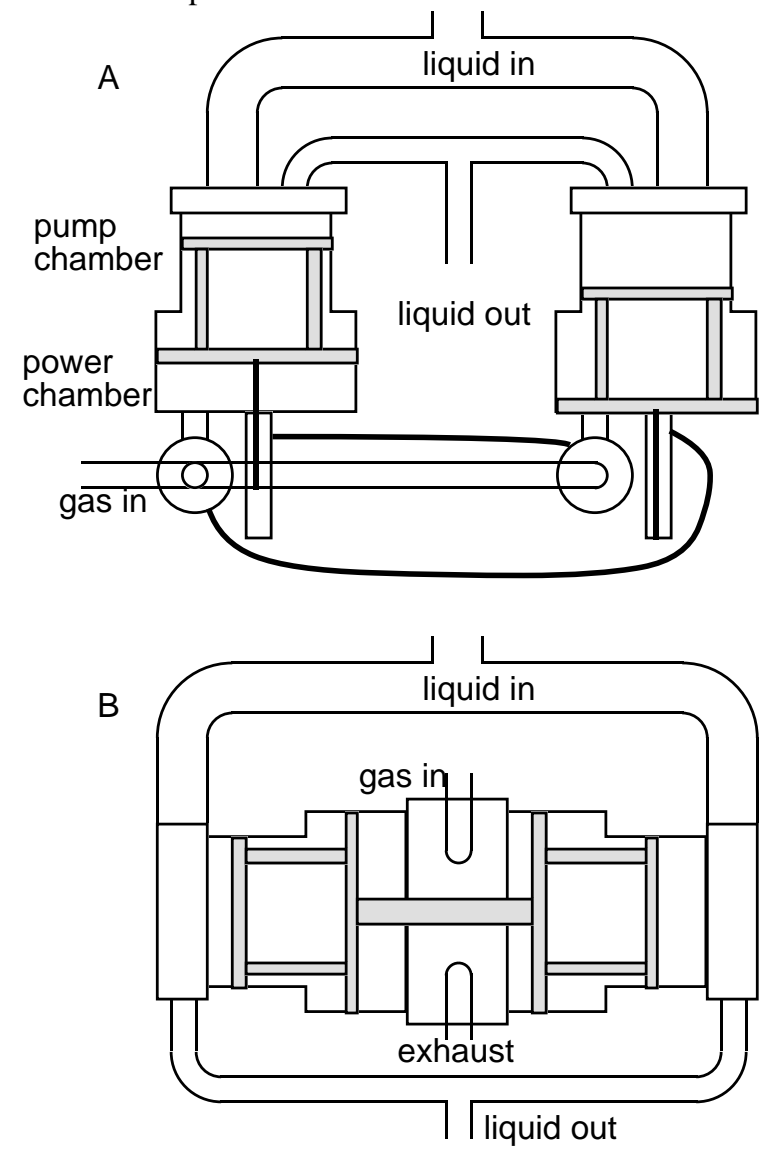

Figure 14. Alternative configurations for piston pumps.

Engine cycles 
The original pumped hydrazine system used a pressureregulated monopropellant gas generator cycle. The greatest difficulty was the fine line between friction and warm gas leakage. This required precision fits for the solid graphite piston rings and valve seals. As implemented, the $\sim 950 \mathrm{~K}$ warm gas leakage was roughly half the total gas generator flow. ${ }^{5}$ It would be worth cooling it to $500 \mathrm{~K}$, since fluoroelastomer seals could then eliminate the leakage, and gas density would not quite double.

The output of a monopropellant gas generator can be cooled against the liquid being pumped. This latter option would receive strong consideration if the hydrazine system were to be implemented again. The notion of low cost pumps made with aluminum and o-rings has stimulated thinking about other engine cycles which drive pumps with relatively cool gas. Possibilities include vapors of oxygen, carbon monoxide, or methane produced on Mars.

The above considerations have inspired an idea for hypergolic bipropellants, presented in Figure 15. The fuel side uses a catalytic gas generator cycle similar to that implemented previously. Nitrogen tetroxide is used to cool the decomposed hydrazine. The resulting superheated nitrogen dioxide gas powers the oxidizer pump. Several regulators and valves are omitted from the sketch.

The most difficult problems encountered previously appear to be solved. In particular, the pumps are driven by propellant-compatible gases which are cool enough for soft seals. The pumps are identical, and their exhaust gases can be used to maintain tank pressures. The extra exhaust can produce some thrust, as indicated in the diagram.

System startup would use bootstrapping from tank pressure, just as the monopropellant system did. The fuel side would be brought to operating pressure first, and elastomer gas seals would keep themselves cool by preventing leakage flow. The oxidizer side would then be bootstrapped as the gas generator flow is increased. Timing is obviously important, to keep gas temperatures within limits during startup.

Assuming $600 \mathrm{~K}$ and $7 \mathrm{MPa}$ steady conditions for the decomposed hydrazine (m.w.=15) driving the fuel pump, the gas density would be 21 grams/liter. A pump area ratio of 1.5 as used in the past would require $3 \%$ of the hydrazine to flow through the gas generator.

The molecular weight of the oxidizer is unfortunately high, at 46 in the dissociated vapor phase. Density would be 65 $\mathrm{g} / \mathrm{l}$ at the above temperature and pressure, so that nearly $7 \%$

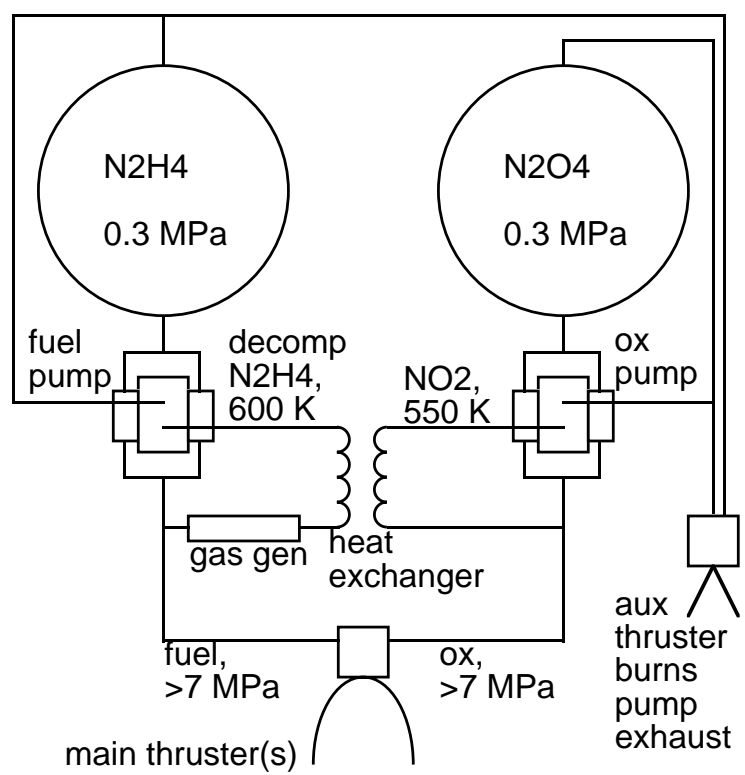

Figure 15. Simplified schematic of pump-fed propulsion using hypergolic bipropellants.

of the oxidizer would need to flow through the heat exchanger, for a mass flow $\sim 2.5$ times that of the catalytic gas generator.

The combined heats of vaporization and dissociation of $\mathrm{N}_{2}$ $\mathrm{O}_{4}$ are roughly $600 \mathrm{~J} / \mathrm{g}$. This would absorb a large fraction of the gas generator enthalpy. The latter varies between 1600-3400 J/g, depending on the extent of ammonia dissociation. Desired pump-drive temperatures can therefore be obtained by varying the amount of catalyst.

One or more oxygen-rich auxiliary thrust chambers would be needed to combust most of the pump exhaust, at roughly $1 \mathrm{MPa}$. These small thrusters could possibly be used for attitude control. Alternatively, the gases could be injected into the main nozzle downstream of the throat. The net Isp for the engine would be well within $5 \%$ of that obtained in the main thrust chamber(s).

In the worst case of no auxiliary combustion, the $\sim 5 \%$ Isp reduction from 315 to $300 \mathrm{~s}$ raises the stage propellant fraction in Figure 5B from $84 \%$ to $86 \%$. Clearly, if pumps reduce the fractional mass sum of engines and tanks from $15 \%$ to $5 \%$, there is a large gain and no cause for concern over lost Isp.

\section{Alternative propellants}

Lower Isp may also be acceptable if tankage mass can be reduced by using less hazardous propellants. For example, gelled hypergolics would be safer than hypergolic liquids in a common bulkhead tank. 
An extreme case of reducing Isp to accommodate the unitized spheroid design would be to eliminate the common bulkhead and simplify the system to hydrazine alone. Stage propellant fractions would be extreme at $90 \%$ (Figure 6 ), but the masses of demonstrated hardware components support the feasibility. This option would require the least departure from proven capability. In particular, the existing thrust chambers are the only ones (among all possible propellants) that already meet both thrust/weight and lifetime requirements on the smallest scales of interest.

The minimally hazardous combination of hydrogen peroxide and hydrocarbon is both non-hypergolic and immiscible. Storage in a common-bulkhead tank should surely be acceptable. If the hydrocarbon is pentane, it would be liquid at both earth and Mars ambient temperatures. Its superheated vapor could drive the fuel pump. The heat of course would come from catalyticallydecomposed $\mathrm{H}_{2} \mathrm{O}_{2}$, with the engine cycle being a mirror image of Figure 15. This warm gas may be cooled to below $600 \mathrm{~K}$ before its steam component condenses at pressures of interest for the oxidizer powerhead.

A simpler engine cycle would drive both pumps with decomposed $\mathrm{H}_{2} \mathrm{O}_{2}$. This could operate effectively with longer-chain hydrocarbons such as kerosene. If the gas is cooled to temperatures compatible with elastomer pump seals, it would not ignite any leakage in the fuel pump. Development issues for $\mathrm{H}_{2} \mathrm{O}_{2}$-hydrocarbon include thrust chamber ignition, 33 and the need to coat the oxidizer tank with a polymer for trans-Mars storage.

A cryogenic propellant derived from Mars' atmosphere could be pumped to high pressures by some of its own superheated vapor. For example, a gas/liquid piston area ratio of 3 could deliver liquid at 1.5 times the gas pressure, while expelling exhaust at half of its initial pressure. Pumping liquid oxygen to $9 \mathrm{MPa}$ would require only $10 \%$ of the oxygen for pump power $(600 \mathrm{~K}$ ideal gas). A $3 \mathrm{MPa}$ loss through the heat exchanger would be allowed. Auxiliary thrusters would receive gas at $3 \mathrm{MPa}$, with surge flow when the pump exhaust valve opens.

A full-flow expander cycle may require a large piston area ratio, e.g. 10 , to minimize pump exhaust pulsations. The liquid discharge could be at 1.5 times the pump drive pressure, while the gas loses only $15 \%$ of its pressure through the powerhead. The pump drive gas density would be $114 \mathrm{~g} / \mathrm{l}$ (1/10 that of liquid oxygen), so its pressure could be as high as $18 \mathrm{MPa}$ (at $600 \mathrm{~K}$ ). Such a full-flow design would require a heavier pump assembly. The gas cylinder(s) would be large, and $85 \%$ of the piston load would need to be transferred from the working chamber to the exhausting chamber. The best configuration is therefore a single piston in a double acting gas cylinder.
In summary, pump-fed engines can potentially be developed for any of the propellant combinations under consideration for Mars ascent. However, the design of pumps, engine cycles, and associated hardware is intertwined with the issue of choosing the best propellants.

\section{Development considerations}

Creating unique pump fed rocket engines for a single mission may be perceived as prohibitively expensive. It is therefore noteworthy that the 6-year pumped hydrazine project at LLNL and subcontractors had a total cost below $\$ 20 \mathrm{M}$. This kind of effort is affordable within Mars mission budgets, especially considering the alternative. Avoiding miniature engine development requires scaling up, resulting in $\$ 500 \mathrm{M}$ in earth launch costs per mission.

In any case, initial exploratory steps can be taken within a modest budget. Fabrication and qualification of 10-100 liter tanks which carry 30-50 times their mass in propellants should proceed. This is critical to the feasibility of small Mars ascent vehicles, regardless of the propellant choice. If such lightweight tanks can withstand high pressures, then pressure-fed operation would remain under consideration. Otherwise, demonstrating low-pressure $2 \%$ tankage would pave the way for using pumps. The conceptual design of tank-as-structure stages should be closely connected to any such tank development.

There are a number of ways in which miniature pump technology can advance on a modest budget. Working toward robust designs, with inert fluid testing, is an obvious example. Low mass, low leakage, lifetime, and temperature capability must all be demonstrated. On the low end of the temperature range, proof-of-principle tests for expander cycles can be conducted with liquid nitrogen.

\section{Propellant hazards}

For conventional options, safety concerns intrinsic to extremely lightweight hardware for hypergolic toxic liquids must be addressed. Space propulsion companies today serve commercial and government markets with gradually improving products for earth satellites. Risking test facilities and personnel on highly-innovative single-use developments is undesirable from their point of view.

An example is that a high temperature gas and a toxic propellant together in a heat exchanger are considered risky. It is encouraging that TRW's recently-developed Secondary Combustion Augmented Thruster (SCAT) demonstrates feasibility in a space application. ${ }^{20}$ Nitrogen tetroxide is used to cool the combustion chamber before mixing with decomposed hydrazine. 
Such regenerative cooling may also be the answer to meeting life requirements with the compact high pressure chambers needed for Mars ascent. SCAT itself however is heavy at $2 \mathrm{~kg}$ for $50 \mathrm{~N}$ thrust; it lies among conventional thrusters in the upper left of Figure 10. The need for sufficiently compact and lightweight thrusters remains an open development issue for all propellant candidates except monopropellant hydrazine.

\section{Less hazardous propellants}

Nontoxic propellants can contribute significantly to costeffective learning about pump-fed system issues, whether or not the same propellants are ultimately used to perform the mission. Startup transients, vibration, and the pulse response of pump-fed engines all need to be understood better. Small scale systems can be tested in labs which cost less than traditional rocket test facilities, in the absence of propellant exposure hazards. Stage-design issues could also be worked out with minimally-hazardous propellants. These include component locations and interfaces, and lightweight directional control capability.

It is notable that prototype Mars rovers are routinely fieldtested from the earliest stages, whereas the toxicity of conventional propellants severely curtails field testing of complete propulsion systems. The Lunar Landing Research Vehicle (LLRV) was substituted for the Apollo Lunar Module in terrestrial flight tests. It was propelled by a kerosene air-breathing engine, with hydrogen peroxide thrusters for precise control. Such a nontoxic, storable propellant approach would permit proving the guidance and staging capability of miniature Mars ascent vehicles.

The cost advantages of friendly propellants are not confined to bold innovation in rocket development and terrestrial flight testing. Earth launch range operations for the actual Mars mission would be affected as well.

\section{Propellants produced on Mars}

Most of this paper has emphasized conventional propellants, primarily because a hardware record exists to support the quantitative analyses and detailed discussions presented herein. There is no intent to exclude any of the alternatives under consideration. ${ }^{34}$

For Mars in-situ propellant options, the design and development of sufficiently lightweight hardware for Mars ascent needs to become an integral part of established efforts in the field. This includes tanks, insulation, and probably pumps, as well as thrust chamber demonstrations. Dewar tanks would be too heavy to include on a Mars ascent vehicle of any size. Therefore, the problem of cryogenic boiloff from the ascent vehicle's tanks before launch needs attention, for instance. Very lightweight hardware is needed for automatic filling and disconnect, at least on the flight side. The mass of support equipment which must be transported to Mars is of secondary importance, but it will certainly be a challenge to make it lighter than the propellant produced, for Delta II class missions.

\section{Discussion}

Space propulsion technology has earned a well-deserved reputation for being reliable and available when needed. An unfortunate side effect has been the widespread assumption that all maneuvers of interest can be readily performed. The reduction of vital activity has even resulted in the shutdown of research facilities and some loss of expertise over the past several decades.

In truth, it is largely by coincidence that planetary exploration programs have been able to make extensive use of satellite propulsion technology. Entering GTO from LEO is similar to leaving LEO on an interplanetary trajectory. Planetary orbit insertion burns are similar to circularizing from GTO into GEO. All these maneuvers are characterized by modest velocity changes at low acceleration.

Ongoing advances in space propulsion are currently driven by the needs of communication satellites. The former include electric propulsion, which is ideally suited to orbit maintenance. Liquid apogee engines and chemical attitude control thrusters continue to improve slowly, but their thrust/weight ratios are only of secondary importance.

The maneuvering requirements $(\Delta \mathrm{v}$ and acceleration) for Mars departure are vastly different from the needs of earth satellites. Even among planetary scientists and leaders of exploration efforts, the challenge of returning from Mars has been under-appreciated. In order for Mars sample return to succeed, requests for proven and reliable rocket technology must be replaced with funded encouragement to innovate boldly.

\section{Conclusion}

The cruel combination of Mars-to-earth astrodynamics and mission budget caps requires a miniature launch-vehicle. Currently affordable mission options require high-thrust stages between 25 and $1000 \mathrm{~kg}$, of which $75 \%$ to $90 \%$ is propellant. This size range could be scaled up to the extent that propellants produced on Mars can be heavier than the extra hardware needed to support in-situ propellant operations. 
This paper has reviewed the propulsion hardware record on the size and mass scales of interest. For any given combination of stage count, propellant choice, and mission scenario (rendezvous or direct to earth), it is clear that new, customized rocket hardware is needed.

For the smallest stages, basic technology advances are necessary to simultaneously reduce the masses of propellant tanks and engines to acceptable fractions of stage mass. Additionally, the mass of structure, insulation, and other stage hardware must be absolutely minimized.

The solution suggested herein is to apply design principles which are routinely used for large earth launch vehicles. These include using sheet metal tank walls as primary vehicle structure, and pumping propellants to high pressure, compact thrust chambers. Past developments by the author and colleagues at several organizations have already proven that this can be done, on the smallest scale of interest.

Miniature stages to be developed for Mars return will be applicable to other missions which currently cannot be performed. These include lunar surface exploration on a tiny scale. Landing on and departing from Europa will also be within reach, since this moon of Jupiter has a mass and size similar to earth's moon. Lastly, the technology could be used atop the smallest earth launch vehicles, to accelerate microspacecraft onto their final trajectories.

\section{$\underline{\text { Acknowledgments }}$}

The author's familiarity with Mars exploration issues is owed to many professionals in the field. Those not already listed in the references include Larry Lemke of NASA ARC, Donna Shirley of the Jet Propulsion Laboratory, Jerry Sanders at NASA JSC, George Cain of LockheedMartin Astronautics, and Preston Carter of LLNL.

This work was sponsored by the U.S. Government and performed by the University of California Lawrence Livermore National Laboratory under Contract W-7405Eng-48 with the U.S. Dept. of Energy.

\section{$\underline{\text { References }}$}

1. Wallace, R.A., R.T. Gamber, et al, Low Cost Mars Sample Return Mission Options, AIAA 96-0336, 1996.

2. Wercinski, P.F., Mars Sample Return: A Direct and Minimum-Risk Design, J. Spacecraft 33(3) p. 381, 1996.

3. Guernsey, C.S., Mars Ascent Vehicle (MAV) Fact Sheet, JPL Memorandum, Spring 1996.

4. Whitehead, J.C., Single Stage to Orbit Mass Budgets Derived from Propellant Density and Specific Impulse, AIAA 96-3108, 1996.
5. Whitehead, J.C., L.C. Pittenger, N.J. Colella, Design and Flight Testing of a Reciprocating Pump Fed Rocket, AIAA 94-3031, 1994.

6. Weaver, W.L., Mars Surface-to-Orbit Vehicles for Sample Return Missions, J. Spacecraft 11:6, June 1974.

7. Anon., Model Specification for the TE-M-951-1, ASAS Kick Stage, Thiokol Corporation, TEMS-41, Feb 1994.

8. Wiley, S., G. Herbert \& L. Mosher, Design and Development of the NEAR Propulsion System, AIAA 952977, 1995.

9. Anon., Deep Space Program Critical Design Review, Naval Research Lab, Nov. 16-18, 1992.

10. Bryant, K., C. Knight, R. Hurtz, Planetary Lander Vehicles Utilizing LEAP Technology, AIAA 94-2748, 1994.

11. Whitehead, J.C., Propulsion Engineering Study for Small-Scale Mars Missions, UCRL-CR-122442, Univ. of Calif. Lawrence Livermore National Lab, September 1995.

12. Richards, G.R., J.W. Powell, The Centaur Vehicle, JBIS Vol. 42, p.99, 1989.

13. Tam, W.H., W.D. Lay, et al, Design, Development, Qualification, and Manufacture of the HS-601 Propellant Tank, AIAA 96-2748, 1996.

14. Shesta, J., Construction of Tanks-No Matter How Large, Cubic Capacity Per Pound of Tank Remains Constant, Astronautics 8(39) p. 13-16, January 1938.

15. Tam, W.H., M.J. Debreceni, W.D. Lay, D. Gallet, Design and Development of the NEAR Oxidizer Tank, AIAA 95-2528, 1995.

16. Rollins, J.R., et al, Structural and NDE Considerations in the Design of Titanium Satellite Propellant Tanks, AIAA 94-3107, 1994.

17. Papanicolopolos, A., private communication, Structural Composites Industries, 1997.

18. Wichmann, H., M. Fitzsimmons, Miniature High Performance Delta V Engine, AIAA 93-2582, 1993.

19. Campbell, J.G., J.R. Riccio, High Performance Earth Storable Rocket Engine, AIAA 95-2399, 1995.

20. Sackheim, R.L., TRW's Family of High Performance Spacecraft Engines: Status and Impact, Proceedings of the JANNAF Propulsion and Joint Subcommittee Meetings, Albequerque, December 1996.

21. Brewster, G., MR-125 Thruster Life Demonstration Test, Olin Aerospace Co. report 94-R-1897, Sep 1994.

22. Maybee, J.C., D.G. Swink, J.C. Whitehead, Updated Test Results of a Pumped Monopropellant Propulsion System, JANNAF Propulsion Meeting Proceedings, CPIA Pub. 602 Vol. 1, p. 131, November 1993.

23. Frei, T.E., J.C. Maybee, J.C. Whitehead, Recent Test Results of a Warm Gas Pumped Monopropellant Propulsion System, AIAA 94-3393, 1994.

24. Guernsey, C.S., private communication, August 1996. 
25. Coleman, G., private communication, McDonnell Douglas Astronautics Co., 1997.

26. Guy, L.D., Structural and Decelerator Design Options for Mars Entry, J. Spacecraft 6(1) p. 44, 1969.

27. Mitcheltree, R.A.,, P.A. Gnoffo, Wake Flow About the Mars Pathfinder Entry Vehicle, J. Spacecraft 32(5), Sep-Oct 1995.

28. Sobin, A.J., W.R. Bissell, Turbopump Systems for Liquid Rocket Engines, NASA SP-8107, August 1974.

29. Pauckert, R., D. Crisalli, et al, Flightweight XLR-132 Engine Program, PL-TR-93-3030, USAF Phillips Laboratory \& Rocketdyne, December 1993.

30. Crisalli, D., private communication, Rocketdyne, 1995.

31. Whitehead, J.C., Bipropellant Propulsion with Reciprocating Pumps, AIAA 93-2121, 1993.

32. Whitehead, J.C., Fluid Driven Reciprocating Apparatus, U.S. Patent 5616005, April 1997.

33. Minthorn, M.K., et al, Non Toxic Liquid Bipropellant Divert/ACS Propulsion Technology Demonstration Efforts, Proceedings of the JANNAF Propulsion and Joint Subcommittee Meetings, Albequerque, December 1996.

34. French, J.R., Rocket Propellants from Martian Resources, JBIS Vol. 42 p.167, 1989. 